\title{
Investigation on the pressure behavior of injectors influenced by waterflood-induced fractures: field cases in Huaqing reservoir, Changqing Oilfield, China
}

\author{
Yang Wang ${ }^{1,}{ }^{*}$, Shiqing Cheng $^{1}$, Kaidi Zhang ${ }^{2}$, and Xiaoping $\mathrm{An}^{3}$ \\ ${ }^{1}$ State Key Laboratory of Petroleum Resources and Prospecting, China University of Petroleum, 102249 Beijing, China \\ ${ }^{2}$ Lusheng Petroleum Development Company Limited, SINOPEC Shengli Oilfield Company, 257000 Dongying, China \\ ${ }^{3}$ PetroChina Changqing Oilfield Company, 710018 Xi'an, China
}

Received: 20 July 2019 / Accepted: 20 February 2020

\begin{abstract}
Pressure transient behaviors of water injectors with the influence of Waterflood-Induced Fractures (WIFs) in unconventional tight oil reservoirs are much more complicated than hydraulic fracturing producers due to the variation of the WIF properties in the field-testing period. In this paper, we present the interpretation on five different types of Bottom-Hole Pressure (BHP) responses for water injectors by combining a commercial simulator tool and our proposed models, where the Shrinking Fracture Length (SFL) and Decreasing Fracture Conductivity (DFC) effects are captured for single long WIF while the multiple fracture closures effect is characterized for multiple WIFs. Results show that the commonplace phenomena of prolonged storage effect, bi-storage effect, and interpreted considerably large storage coefficient suggest that WIF(s) may initiate by long-time water injection. Based on this interpreted large storage coefficient, the fracture half-length can be estimated. The upward buckling of pressure derivative curve may not necessarily be caused by closed outer boundary condition, but the Decreasing of Fracture Conductivity (DFC). As for multiple WIFs, they would close successively after shutting in the well due to the different stress conditions perpendicular to fracture walls, which behaves as several unit slopes on the pressure derivative curves in log-log plot. Aiming at different representative types of BHP responses cases in Huaqing reservoir, Changqing Oilfield, we innovatively analyze them from a different perspective and get a new understanding of water injector behaviors, which provides a guideline for the interpretation of water injectors in tight oil reservoirs.
\end{abstract}

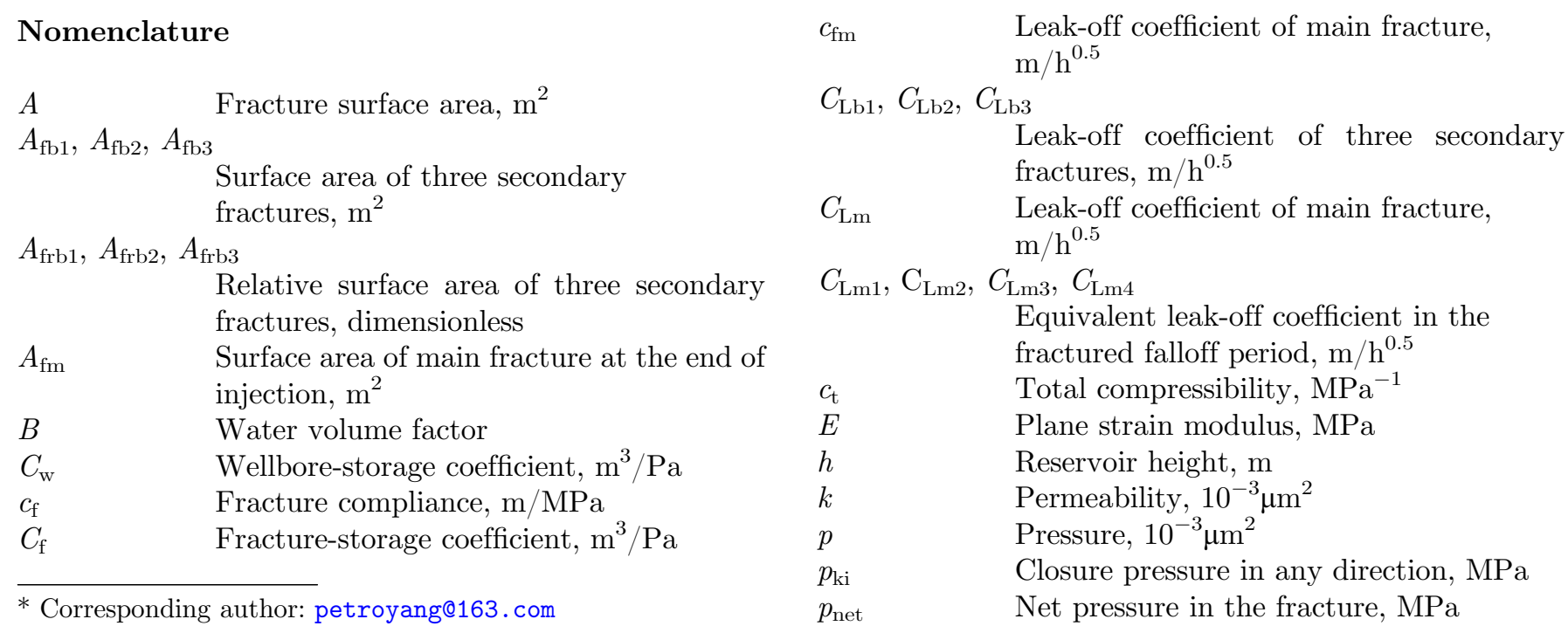




\begin{tabular}{|c|c|}
\hline$p_{\text {shut-in }}$ & $\begin{array}{l}\text { Bottom-hole pressure in the shut-in } \\
\text { moment, } \mathrm{MPa}\end{array}$ \\
\hline$p_{\mathrm{wD}}^{0}$ & $\begin{array}{l}\text { Dimensionless bottom-hole pressure when } \\
\text { fracture begins to shrink }\end{array}$ \\
\hline$q$ & Water injection rate, $\mathrm{m}^{3} / \mathrm{d}$ \\
\hline$r_{\mathrm{p}}$ & $\begin{array}{l}\text { Ratio of permeable fracture surface area to } \\
\text { the gross fracture area, dimensionless }\end{array}$ \\
\hline$R_{\mathrm{F}}$ & $\begin{array}{l}\text { Fracture radius in radius fracture } \\
\text { model, } \mathrm{m}\end{array}$ \\
\hline \multicolumn{2}{|l|}{$S_{\text {choke }}$} \\
\hline & Choked-fracture skin \\
\hline$S_{\mathrm{fs}}$ & Fracture-face skin \\
\hline$t_{\mathrm{p}}$ & $\begin{array}{l}\text { Fractured injection time at the end of } \\
\text { injection, } h\end{array}$ \\
\hline$x_{\mathrm{F}}$ & Fracture half-length, m \\
\hline$x_{\mathrm{F} 0}$ & $\begin{array}{l}\text { Fracture half-length in the shut-in } \\
\text { moment, } \mathrm{m}\end{array}$ \\
\hline$V_{\text {frac }}$ & Volume of the fracture, $\mathrm{m}^{3}$ \\
\hline$V_{\text {frac,mf }}$ & Volume of main fracture, $\mathrm{m}^{3}$ \\
\hline \multicolumn{2}{|c|}{$\begin{array}{r}V_{\text {frac,b1 }}, V_{\text {frac,b2 }}, V_{\text {frac,b3 }} \\
\text { Volume of three secondary fr }\end{array}$} \\
\hline \multicolumn{2}{|c|}{$V_{\mathrm{l}, \mathrm{bf} 1}, V_{\mathrm{l}, \mathrm{bf} 2}, V_{\mathrm{l}, \mathrm{bf} 3}$} \\
\hline$V_{1, \mathrm{mf}}$ & $\begin{array}{l}\text { Flow volume from main fracture into } \\
\text { matrix } \mathrm{m}^{3}\end{array}$ \\
\hline$V_{\mathrm{p}}$ & $\begin{array}{l}\text { Accumulated volume of water injected in } \\
\text { fractured injection period, } \mathrm{m}^{3}\end{array}$ \\
\hline $\bar{w}$ & Fracture width, $\mathrm{m}$ \\
\hline$\Delta t$ & Time interval, $\mathrm{h}$ \\
\hline$\Delta t_{\mathrm{fc} 1}, \Delta t$ & $\begin{array}{l}\text { Fracture closure moment of three sec- } \\
\text { ondary fractures, h }\end{array}$ \\
\hline$\Delta t_{\mathrm{fcD} 1}, L$ & $\begin{array}{l}\Delta t_{\mathrm{fcD} 3} \\
\text { Dimensionless fracture closure moment of } \\
\text { three secondary fractures, dimensionless }\end{array}$ \\
\hline$\alpha$ & Area exponent, dimensionless \\
\hline$\sigma_{\max }$ & Maximum principal stress, MPa \\
\hline$\sigma_{\min }$ & Minimum principal stress, $\mathrm{MPa}$ \\
\hline$\theta$ & $\begin{array}{l}\text { Included angle between the fracture } \\
\text { direction and maximum principal stress, } \\
\text { radian }\end{array}$ \\
\hline$\mu$ & Water viscosity, $\mathrm{mPa} \mathrm{s}$ \\
\hline
\end{tabular}

\section{Subscript}

$\begin{array}{ll}\text { D } & \text { Dimensionless } \\ \text { F } & \text { Fracture } \\ \text { m } & \text { Matrix }\end{array}$

\section{Superscript}

Laplace transform

\section{Introduction}

Waterflooding is one of the most commonly used development methods in the field of petroleum industry and there are growing evidences showing that water injection may induce formation fracturing [1-5]. The long WIFs may be caused by plugging effects, depletion (poro-elastic), thermal effects, and so on [6, 7]. As shown by Wright et al. [8] in West Texas by tiltmeter data, the half-length of the WIFs can reach a surprising $450-650 \mathrm{ft}$ (70-100\% of well spacing) as seen in Figure 1.

These WIFs may be beneficial in improving injectivity or injection rates. However, if they are not managed adequately, it could be of great disadvantage (e.g., prematured water breakthrough in producers, steep rise in oilfield overall water-cut profiles, unpredictable flood pattern, poor sweep), which would lead to undesired oilfield performance [9]. Figure 2 shows an example in a certain oilfield. The inverted nine-spot pattern is adopted in this field (Fig. 2a). Influenced by WIFs in West-East direction, the performances of production wells in different positions are totally different. Quick water breakthrough, accompanied with low oil rate and high water cut, occurs in producers along the WIF direction (Fig. 2b) while long-term low production rate is sustained for producers that perpendicular to WIF (Fig. 2c). Such dynamic behaviors of WIFs need to be timely and carefully evaluated in the waterflooding program. Since it is difficult to detect the features of the reservoir and fractures underground, Pressure-Transient Analysis (PTA) becomes a desirable choice to evaluate well performances and reservoir characteristics (i.e., average formation permeability, wellbore-storage effects, skin factor, fracture properties) on the basis of Bottom-Hole Pressure (BHP) data in a more economical and environmentally friendly way.

This paper aims at presenting several representative BHP responses of water injectors with WIF(s). Firstly, the dynamic evolution of $\mathrm{WIF}(\mathrm{s})$ in water injector is presented. After that, five common and typical pressure responses of water injectors in Huaqing reservoir, Changqing Oilfield, are interpreted by combining a commercial simulator (KAPPA Workstation 5.12) and models we proposed $[10,11]$ together to give us a new and comprehensive understanding of the BHP behaviors in water injectors.

\section{The dynamic evolution of WIF(s) in water injector}

We divide the whole water injection process into four stages as following (Fig. 3).

\subsection{Reservoir injection}

Generally, there are lots of closed mini-fractures under reservoir condition in tight formation. Due to the limited absorption capacity, the BHP of water injector increases rapidly as the process of water injection. When the formation pressure exceeds fracture opening pressure, the original 


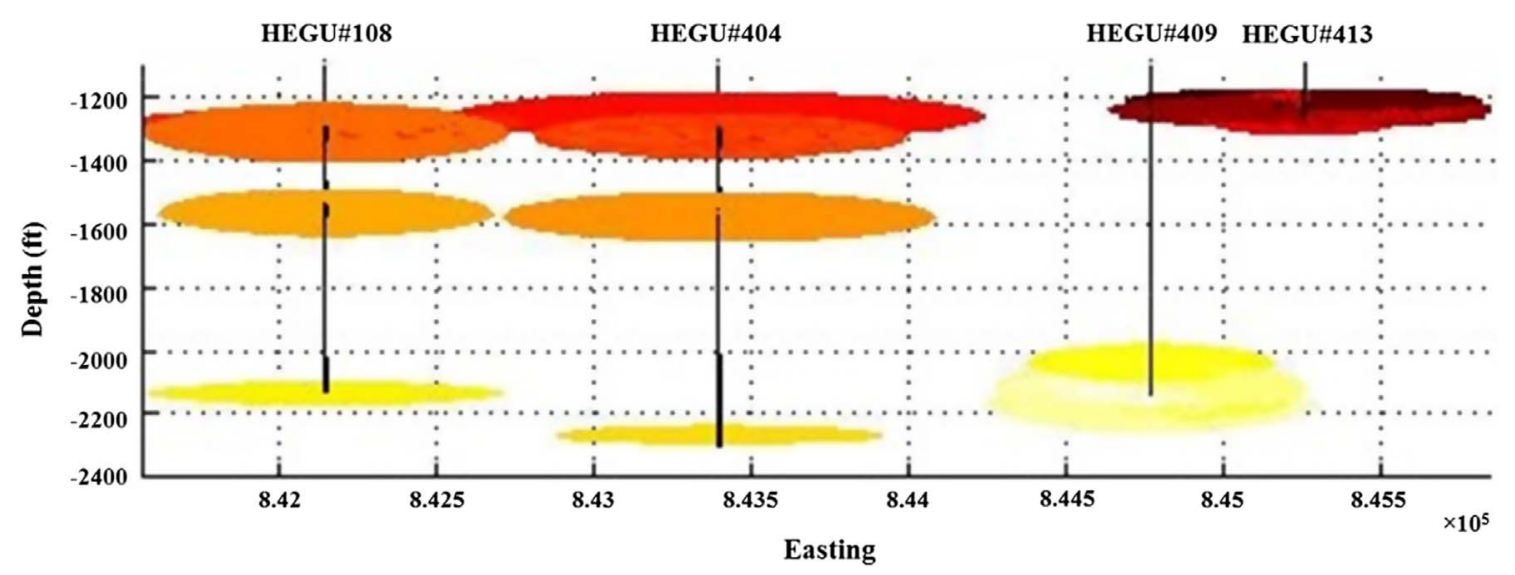

Fig. 1. Sideview for all tiltmeter mapped fractures in the waterflood project in West Texas [8].

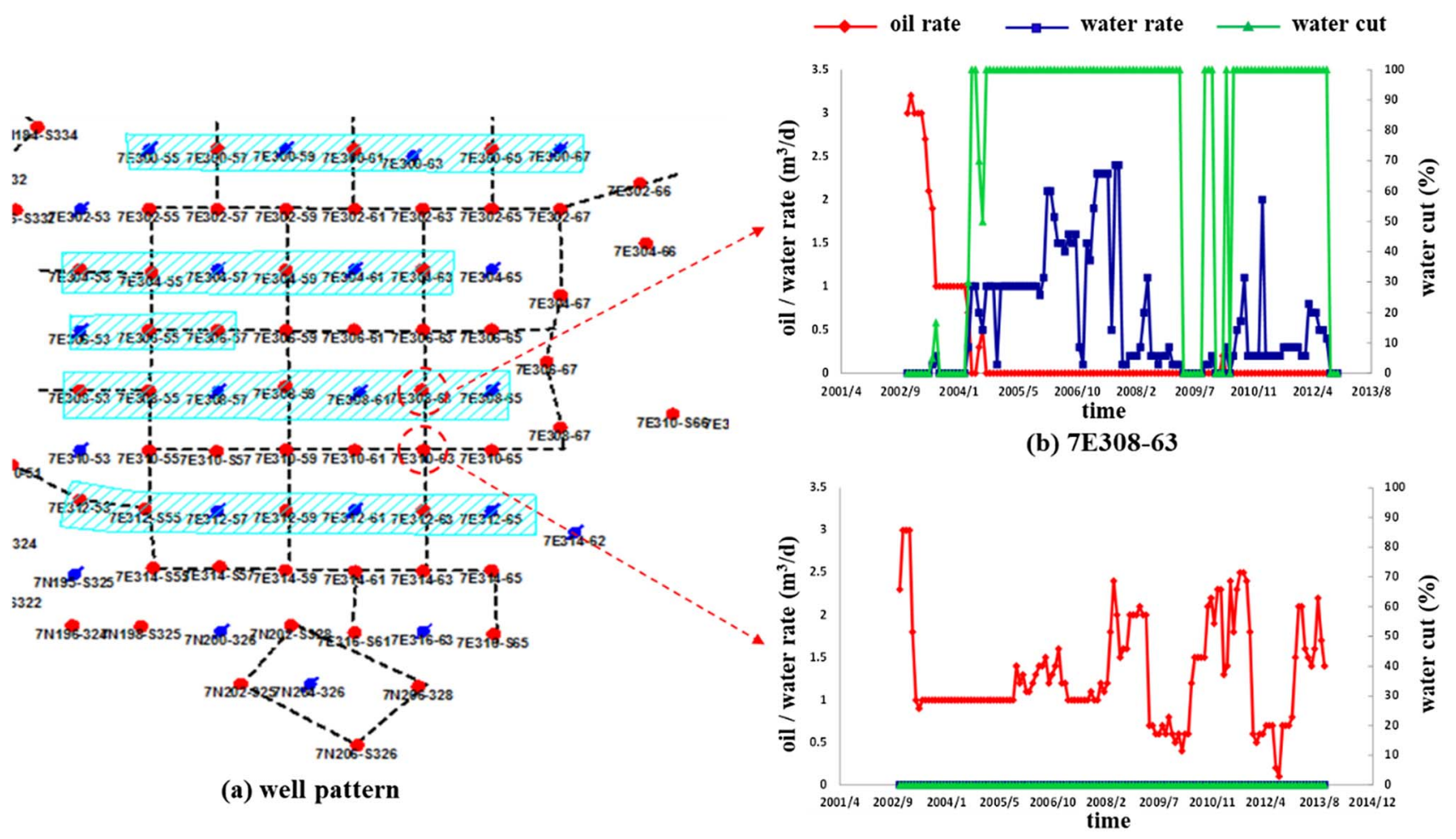

(c) 7E318-63

water injector producer

fracture direction

Fig. 2. Well pattern and production dynamics in a certain oilfield.

closed mini-fractures begin to expand (Fig. 3a). The opening of mini-fractures increases the effective permeability of inner region. If the formation pressure exceeds fracture propagation pressure, the expanded mini-fractures extend continuously and communicate with each other and finally, a connected long WIF forms near the water injector (Fig. 3b).

\subsection{Fractured injection}

As the continuity of water injection, if the water injection rate into the fracture exceeds the rate flow from fracture to the matrix, the pressure in the fracture increases and then the fracture would continue to grow until the injection and leak-off rate balance again [12]. According to 


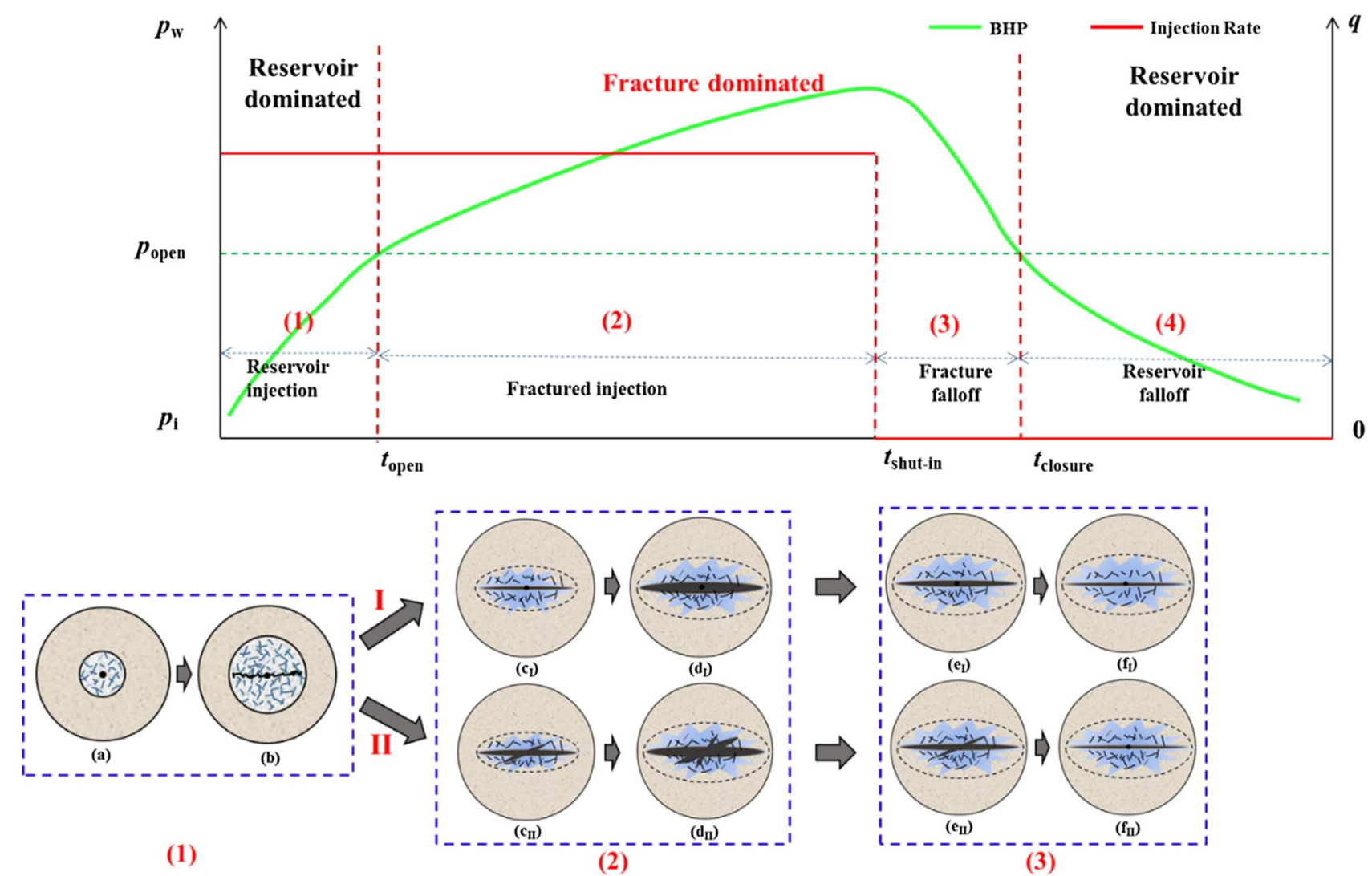

Fig. 3. Schematic of dynamic evolution of WIF in water injector.

monitoring and analysis results in oilfields, two scenarios are given:

- Single WIF: Generally, the WIF seems to follow the maximum stress direction [13, 14], which can be easily understood because the stress perpendicular to the fracture walls for maximum principal stress direction is least. This long fracture continues to grow as the process of water injection, which can even reach several times of well spacing. The waterfloods in Western Canada [12] and Ordos basin in China validate this phenomena. This dynamic process is sketched in Figures $3 \mathrm{c}_{\mathrm{I}}$ and $3 \mathrm{~d}_{\mathrm{I}}$.

- Multiple WIFs: The secondary fractures may also initiate when the pressure in the fracture exceeds the stress perpendicular to fracture walls in specific direction. As the continuously process of water injection, both main fracture and secondary fractures continue to propagate, which shown in Figures $3 c_{I I}$ and $3 \mathrm{~d}_{\mathrm{II}}$.

\subsection{Fracture falloff}

Different with the propped (static) hydraulic fractures around producers, the WIF(s) around water injectors would close gradually after shutting in the well because there are no proppants inside (full of water). Similarly, two scenarios are shown for single WIF and multiple WIFs, respectively:

- Single WIF: One may easily imagine that the fracture width reduces as fracture closing, which results in the DFC effect. In the meantime, experiments from van Dam et al. [15] showed that the fracture surfaces make mechanical contact at the tip first, and then subsequently towards the wellbore, which is called Shrinking Fracture Length (SFL) in this study. This dynamic process is shown in Figures $3 \mathrm{e}_{\mathrm{I}}$ and $3 \mathrm{f}_{\mathrm{I}}$.

- Multiple WIFs: As for multiple fractures, due to the different stress conditions in the WIFs, they may not close at the same time, but successively. This can be explained as the equation (1): the closure/ opening pressure $\left(p_{\mathrm{ki}}\right)$ of WIFs in a specific direction, which depends on the maximum principal stress, $\sigma_{\max }$, minimum principal stress, $\sigma_{\min }$ and included angle between the fracture direction and maximum principal stress, $\theta$. Obviously, the closure pressure $\left(p_{\mathrm{ki}}\right)$ increases as the increase of included angel $(\theta)$, and equal to $\sigma_{\min }$ and $\sigma_{\max }$ in maximum and minimum principal stress directions, respectively. Thus, the WIF with larger included angle closes first, and lastly to the maximum principal direction. This dynamic process is shown in Figures $3 \mathrm{e}_{\mathrm{II}}$ and $3 \mathrm{f}_{\mathrm{II}}$.

$$
p_{\mathrm{ki}}=\sigma_{\min }+\left(\sigma_{\max }-\sigma_{\min }\right) \sin \theta,
$$




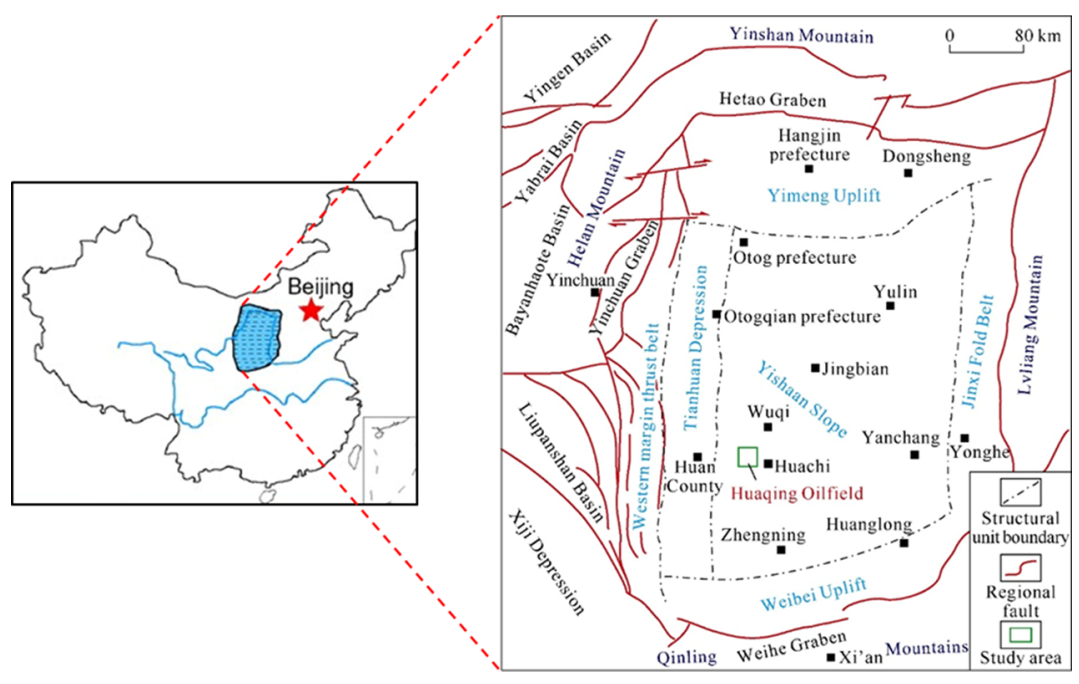

\begin{tabular}{|c|c|}
\hline Parameter & Vaule \\
\hline \multicolumn{2}{|l|}{ Reservoir } \\
\hline Porosity (\%) & $6-16$ \\
\hline Permeability (mD) & $0.04-0.6$ \\
\hline Compressibility $\left(\mathrm{MPa}^{-1}\right)$ & 0.0014 \\
\hline Initial Pressure (MPa) & 16.73 \\
\hline Pressure Gradient (MPa/100m) & 0.79 \\
\hline Reservoir Temperature $\left({ }^{\circ} \mathrm{C}\right)$ & 69.7 \\
\hline Temperature Gradient $\left({ }^{\circ} \mathrm{C} / 100 \mathrm{~m}\right)$ & 3.2 \\
\hline \multicolumn{2}{|l|}{ Fluid } \\
\hline Initial Oil Saturation (\%) & 55.13 \\
\hline Oil Viscosity (mPas) & 4.56 \\
\hline Water Viscosity (mPas) & 0.55 \\
\hline Oil Density $\left(\mathrm{g} / \mathrm{cm}^{3}\right)$ & 0.723 \\
\hline
\end{tabular}

Fig. 4. Location and basic parameters of Huaqing Oilfield (modified from Su et al. [16]).

Table 1. Summary of field cases.

\begin{tabular}{ll}
\hline Cases & \\
\hline Case $\# 1-$ Well A & Composite radial model \\
Case $\# 2-$ Well B & Bi-storage (wellbore storage + variable fracture storage) effect \\
Case $\# 3-$ Well C & Prolonged storage effect \\
Case $\# 4-$ Well D & Upward buckling of pressure and its derivative curve in the late time caused by DFC \\
Case $\# 5-$ Well E & Multiple storage effect caused by successive fracture closures \\
\hline
\end{tabular}

\subsection{Reservoir falloff}

At this stage, the WIFs have already closed completely, which means that the pressure drop of the injector is reservoir dominated. However, one should note that the permeability of closed fracture is still larger than matrix permeability due to the fracture roughness, especially for tight reservoirs.

\section{Field cases}

Huaqing reservoir is located in the central south of the Yishan slope in the Ordos Basin (Fig. 4). The Chang-6 formation is the most developed and best oil-bearing in this field, which is dominated by sandy debris flow and turbidity deposits. With fine rock particle size, high clay content, and complex rock composition, Huaqing reservoir is characterized as strong heterogeneity, low porosity and low permeability. The porosity for Chang- 6 formation in this area ranges from $6 \%$ to $16 \%$ while permeability ranges from $0.04 \mathrm{mD}$ to $0.6 \mathrm{mD}$. Based on the statistics data of cores, thin section observation, and well logging with imaging, we find that mini-fractures are well developed in this field, which largely increases the difficulty of waterflooding management. The average interpreted permeability for water injectors and producers in this field are $2.7 \mathrm{mD}$ and $0.3 \mathrm{mD}$, respectively, which reflects that long-time water injection induces formation fracturing. In this part, five representative wells that influenced by induced fractures in this field are selected (see Tab. 1). Among all the 329 water injectors we analyzed, the numbers of pressure responses that behave like Well A, B, C, D, and E are 94, 19, 43, 31 , and 11. Aiming at these five cases, we try to analyze them by combining a commercial simulator and our models, and provide us a novel understanding of the performance of water injectors in tight oil reservoirs.

\subsection{Case \#1: Well A}

For PTA in well injectors, Morse and Ott [17] developed an unsteady-state pressure analysis method to locate the position of outer radius of water bank. Kazemi et al. [18] proposed an idealized illustration of two- or three zones in liquid-filled reservoir and described the mathematical model in detail. Abbaszadeh and Kamal [19] improved previous 
Table 2. Basic data of Well A.

\begin{tabular}{|c|c|c|c|c|c|}
\hline \multicolumn{6}{|c|}{ (1) Well data } \\
\hline Well name & \multicolumn{2}{|l|}{$\mathrm{A}$} & Type of well & \multicolumn{2}{|c|}{ Water injector } \\
\hline $\begin{array}{l}\text { Water injection rate } \\
\text { Well radius }\end{array}$ & \multicolumn{2}{|c|}{$\begin{array}{l}25 \mathrm{~m}^{3} / \mathrm{d} \\
0.124 \mathrm{~m}\end{array}$} & $\begin{array}{c}\text { Well bottom } \\
\text { Total compressibility }\end{array}$ & \multicolumn{2}{|c|}{$\begin{array}{c}2135.5 \mathrm{~m} \\
0.00178 \mathrm{MPa}^{-1}\end{array}$} \\
\hline \multicolumn{6}{|c|}{ (2) Oil horizon and perforation data } \\
\hline \multirow[t]{6}{*}{ Horizon } & $\begin{array}{c}\text { Reservoir interval } \\
(\mathrm{m}-\mathrm{m})\end{array}$ & Thickness (m) & Porosity (\%) & $\begin{array}{l}\text { Perforation } \\
(\mathrm{m}-\mathrm{m})\end{array}$ & Thickness $(\mathrm{m})$ \\
\hline & $2069.5-2072.6$ & 3.1 & & & \\
\hline & $2072.6-2075.4$ & 2.8 & & & \\
\hline & $2075.4-2085.3$ & 9.9 & & $2076.0-2083.0$ & 7 \\
\hline & $2086.4-2089.0$ & 2.6 & & & 6 \\
\hline & $2089.0-2091.1$ & 2.1 & & $2087.0-2093.0$ & \\
\hline \multirow[t]{6}{*}{ C6 } & 2091.1-2093.1 & 2 & 10.5 & & \\
\hline & $2093.1-2096.5$ & 3.4 & & & \\
\hline & $2097.4-2101.8$ & 4.4 & & $2097.0-2101.0$ & 4 \\
\hline & $2102.6-2106.5$ & 3.9 & & $2103.0-2106.0$ & 3 \\
\hline & $2107.4-2110.5$ & 3.1 & & & \\
\hline & $2110.5-2115.5$ & 5 & & & \\
\hline
\end{tabular}

(3) Test mode

Pressure falloff test

models by taking the variation of fluid mobility and diffusivity in the reservoir into consideration. Then, Kong and $\mathrm{Lu}[20]$ presented an interpretation method for water injector and developed a solving process for two-bank systems that possessing sharp change in interface. The pressure and its derivative curves are plotted in $\log -\log$ coordinate, which has been widely used nowadays.

Basic data of water injector Well A is shown in Table 2 and the corresponding BHP responses in 2006 and 2008 are presented in Figure 5, which behave as composite radial reservoir. We assume that the formation is homogeneous and isotropic with constant thickness, and the interface location of the two-bank system is immobile during the field-testing period. In addition, thermal and gravitational effects are ignored. The commercial simulator (KAPPA Workstation 5.12) is adopted to match these BHP responses. The matching and interpretation results are shown in Figure 5 and Table 3, respectively. Traditionally, the composite radial model in water injector is explained as the fluid mobility contrast in each bank [19]. Based on the discussion of "The Dynamic Evolution of WIF(s) in Water Injector", we think this mobility difference can be reflected in two aspects:

- Water viscosity is generally smaller than oil under reservoir condition.

- Permeability in the inner region is larger than outer region because of the long time water erosion and the re-opening of original closed fractures (see Fig. 3a).
The increasing of inner radius from $42.9 \mathrm{~m}$ in 2006 to $88 \mathrm{~m}$ in 2008 indicates the moving of waterflooding front. At the same time, the increase of permeability from $1.06 \mathrm{mD}$ to $4.48 \mathrm{mD}$ illustrates that the re-activation of original closed fractures improves the effective permeability in the inner region.

Since the field-testing pressure of Well A after 2008 is unavailable, we would like to analyze the performance of this well from dynamic production data to verify the variation of flow pattern during water injection. There are six producers named B1, B2, B3, B4, B5, and B6 around injector Well A (Fig. 6). The production histories of Well B1, $\mathrm{B} 4$, and $\mathrm{B} 6$ are given in Figure 7. It is shown that the water cut of Well B1 surged from $14.18 \%$ to $53.44 \%$ in December 2009 (Fig. 7a) while the water cut of Well B4 soared from $0 \%$ to $92.67 \%$ in October 2009 (Fig. 7b). The unexpected and abrupt water breakthrough in B1 and B4 suggests that the WIF may be induced in $\mathrm{B} 1-\mathrm{A}-\mathrm{B} 4$ direction, which is line with the maximum principle stress direction. The performances of the producers in the two sides of B1-A-B4 are quite different with Well B1 and B4. Taking B6 as a representative, the production history is plotted in Figure $7 \mathrm{c}$, which shows stable oil production and water cut. The distinct behaviors between these wells confirm the existence of WIF in B1-A-B4 direction again. These performances validate the evolution of WIF during water injection process in Figure 3.

One should note that well testing analysis is an inverse question, which suffers from non-uniqueness. This nonuniqueness may come from the reservoir uncertainties itself, 


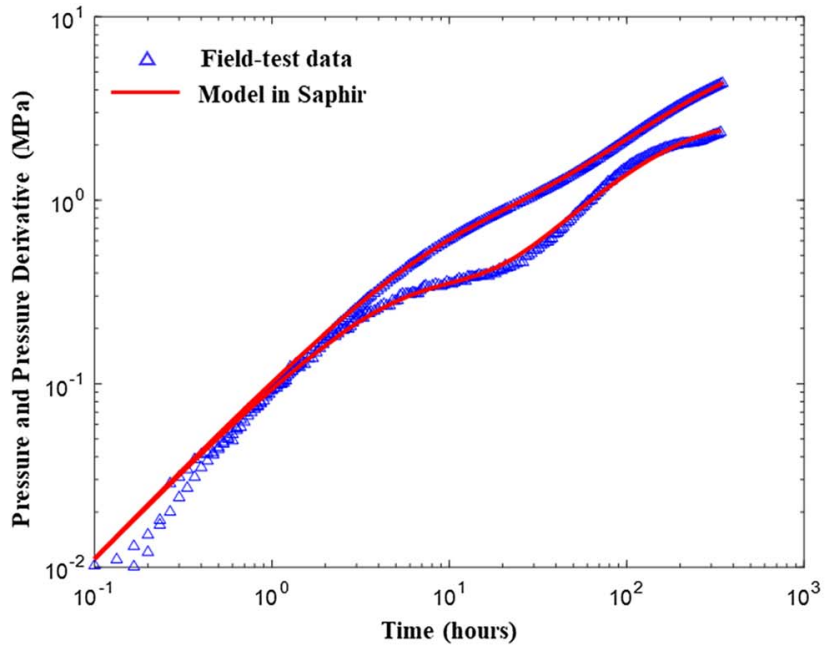

(a)

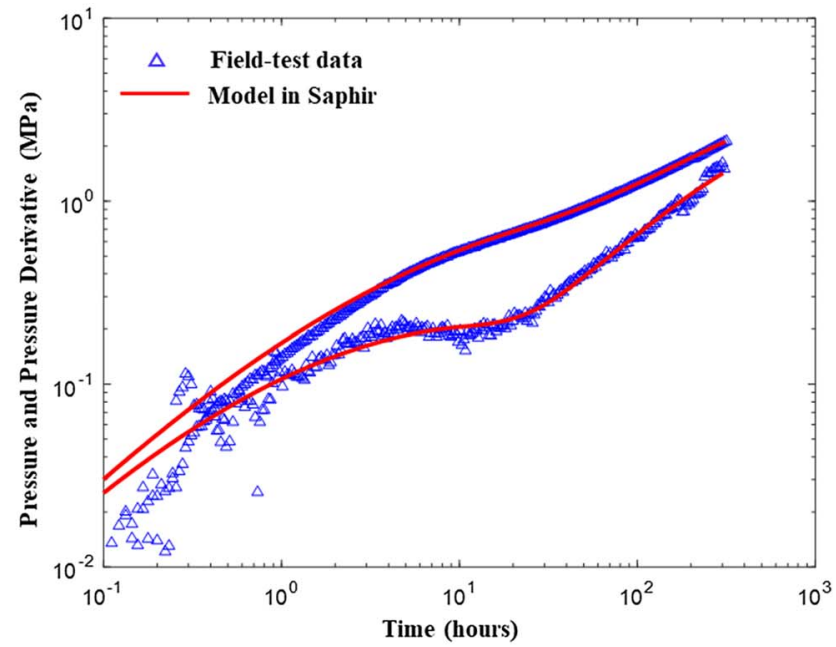

(b)

Fig. 5. Pressure matching results of Well A in (a) 2006 and (b) 2008.

Table 3. Well testing interpretation results for Well A in 2006 and 2008.

\begin{tabular}{lccccc}
\hline Test time & Reservoir model & $\begin{array}{c}\text { Permeability in the } \\
\text { inner region }(\mathrm{mD})\end{array}$ & Radius $(\mathrm{m})$ & Skin & Mobility ratio \\
\hline 2006.6 & Radial composite & 1.06 & 42.9 & -4.39 & 6.3 \\
2008.5 & Radial composite & 4.48 & 88 & -4.42 & 6.62 \\
\hline
\end{tabular}

pressure behavior matching, or the multiple solutions of mathematical models. In this case, one of the disputes may be the model selected for Figure 5b. Before applying radial composite model, the vertical well + one fault and fracture-infinite conductivity models are tried, but unreasonable results are obtained. Therefore, we still use radial composite model to interpret it. In the actual field, different methods are strongly suggested together to lower the uncertainties and increase the confidence of the results.

\subsection{Case \#2: Well B}

There are growing evidences, including step rate test, production history of water injector and producer, well testing analysis, inter-connectivity analysis, indicate the initiation of WIF in water injection process [21]. The fundamental differences between propped hydraulic fractures around producer and WIFs around water injector are summarized in Table 4. Recently, we proposed a new "Fracture - SFL \& DFC" model to characterize the BHP behaviors of water injector with single long WIF considering the fracture properties variation in tight reservoir [10]. The flow between WIF and reservoir is characterized by fracture-storage effect and fracture-face skin while the flow between wellbore and WIF is represented by wellbore storage effect and choked-fracture skin. Compared to the current models [22-27], the novelty of this model is that we take the dynamic variation effects of WIF (e.g., fracture storage effect, SFL, and DFC) after shutting in the well into consideration, which makes our methodology more practical and

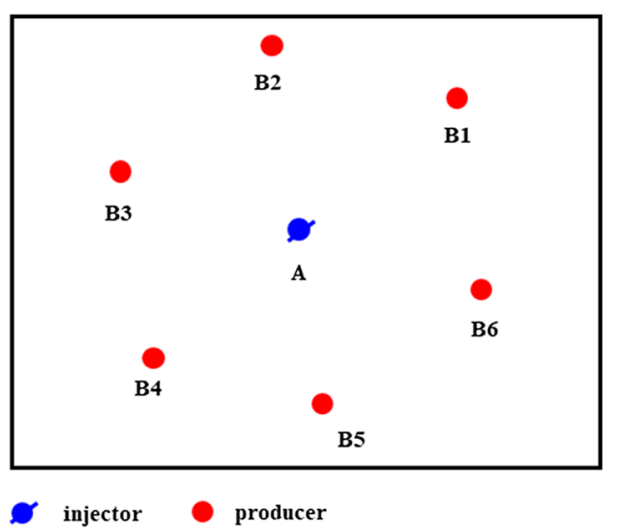

Fig. 6. Well pattern of A.

reliable. A brief introduction of this model is presented in Appendix A.

Case \#2 examines a field case to demonstrate the characteristic of bi-storage (wellbore + variable fracture storage) effect. The basic parameters for Well B is provided in Table 5 and its BHP response is shown in Figure 8. The bi-storage phenomenon, which characterized by two unit slopes on the pressure derivative curve, dominates the whole falloff period and masks the reservoir response. Similar pressure responses have also been found in the Arabian Peninsula [29]. Using our "Fracture - SFL \& DFC" model, we can obtain the matching result of this well, shown in Figure 8. 

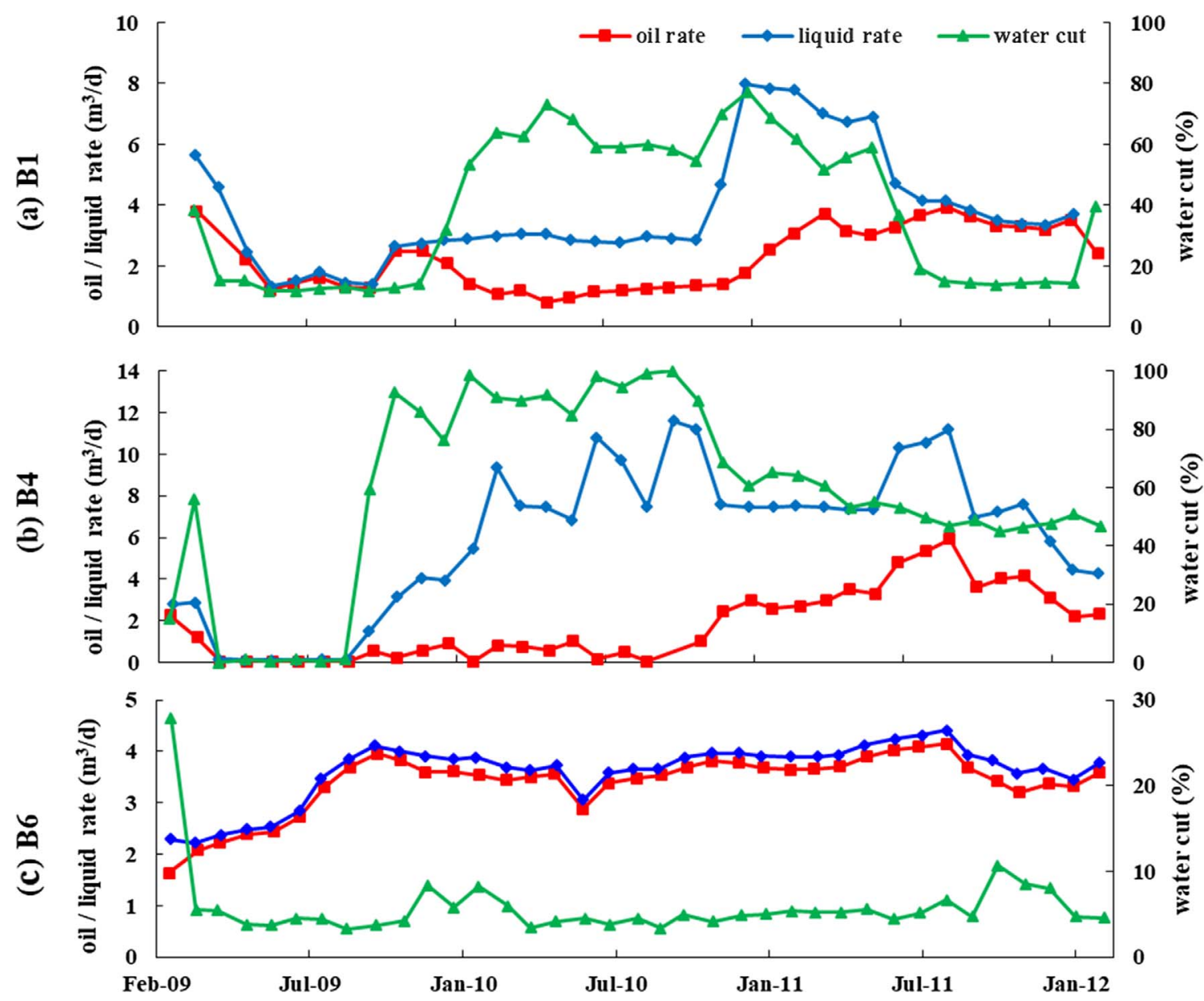

Fig. 7. Production history curves. (a) B1, (b) B4, and (c) B6.

Table 4. Comparison of propped hydraulic fractures around producer and WIFs around water injector (modified from Rizwan [28]).

\begin{tabular}{lcc}
\hline & Propped fractures in producer & Fractures in water injector \\
\hline Type of fracture & Static (non-shrinking) & Non-static (shrinking) \\
Type of PTA used & Pressure build-up & Injection fall-off \\
Fracture induced intentional or accidental? & Intentional & Accidental \\
Proppant used? & Yes & No \\
Fracture closure occurs? & No & Yes \\
Fracture storage occurs? & No & Yes \\
Closure induced flow affects PTA? & Not observed & Strongly observed \\
\hline
\end{tabular}

The interpreted effective permeability is $2.91 \mathrm{mD}$ and the calculated storage coefficient from the long unit-slope line in the pressure derivative curve is considerably large as $8.92 \mathrm{~m}^{3} / \mathrm{MPa}$. The significant large storage coefficient suggests that the WIF(s) that extend to some distances in the reservoir. After shutting the fractured well, the water that stored in the fracture is unloaded and squeezed into reservoir, which is similar to the phenomenon of wellbore storage effect. We call it as fracture storage effect in this paper. The relationship between fracture storage coefficient and fracture half-length is comprehensively discussed based on three 2D models [10], which are,

$$
C_{\mathrm{f}}=\left\{\begin{array}{lll}
\frac{\pi x_{\mathrm{F}} h^{2}}{E} & \text { for } & \text { PKN } \\
\frac{2 \pi x_{\mathrm{F}}^{2} h}{E} & \text { for } & \text { KGD }, \\
\frac{16 R_{\mathrm{F}}^{2}}{3 E} & \text { for } & \text { Radial }
\end{array}\right.
$$


Table 5. Basic data of Well B.

\begin{tabular}{|c|c|c|c|c|c|}
\hline \multicolumn{6}{|c|}{ (1) Well data } \\
\hline Well name & \multicolumn{2}{|l|}{$\mathrm{B}$} & Type of well & \multicolumn{2}{|c|}{ Water injector } \\
\hline $\begin{array}{l}\text { Water injection rate } \\
\text { Well radius }\end{array}$ & \multicolumn{2}{|c|}{$\begin{array}{l}40 \mathrm{~m}^{3} / \mathrm{d} \\
0.124 \mathrm{~m}\end{array}$} & $\begin{array}{l}\text { Well bottom } \\
\text { Total compressibility }\end{array}$ & \multicolumn{2}{|c|}{$\begin{array}{c}2247.0 \mathrm{~m} \\
0.00138 \mathrm{MPa}^{-1}\end{array}$} \\
\hline \multicolumn{6}{|c|}{ (2) Oil horizon and perforation data } \\
\hline \multirow[t]{3}{*}{ Horizon } & $\begin{array}{l}\text { Reservoir interval } \\
\qquad(\mathrm{m}-\mathrm{m})\end{array}$ & Thickness (m) & Porosity $(\%)$ & $\begin{array}{l}\text { Perforation } \\
\quad(\mathrm{m}-\mathrm{m})\end{array}$ & Thickness (m) \\
\hline & $2194.6-2199.2$ & 4.6 & & $2195-2199$ & 4.0 \\
\hline & 2199.9-2202.3 & 2.4 & & & \\
\hline \multirow[t]{3}{*}{$\mathrm{C} 6$} & $2202.6-2204.1$ & 1.5 & 10.31 & & \\
\hline & $2207.7-2212.1$ & 4.4 & & $2208-2210$ & 2.0 \\
\hline & $2216.6-2227.6$ & 11 & & $2217-2221$ & 4.0 \\
\hline
\end{tabular}

(3) Test mode

Pressure falloff test

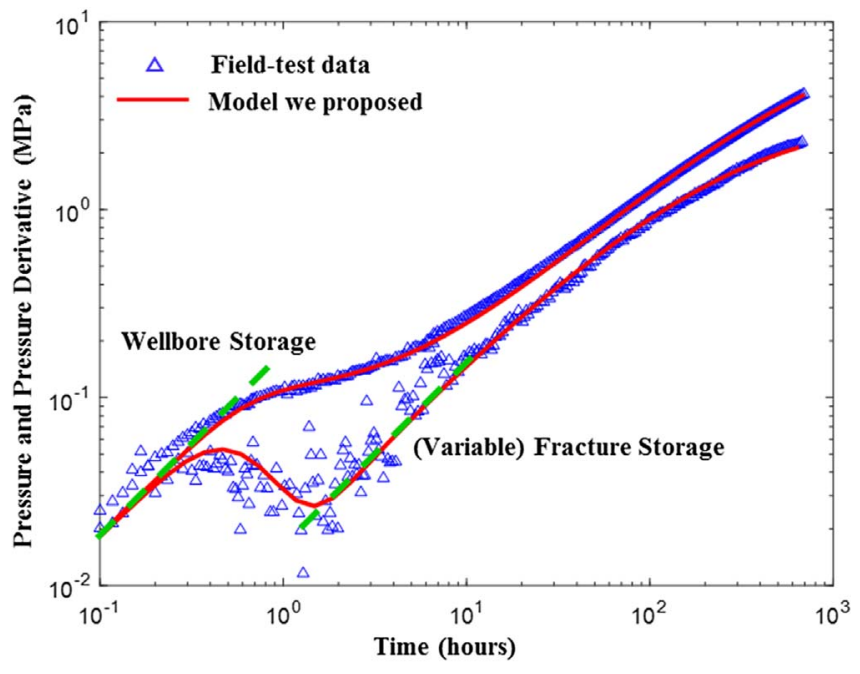

Fig. 8. History matching result of Well B by use of the model we proposed.

where $C_{\mathrm{f}}$ is fracture storage coefficient, $x_{\mathrm{f}}$ is fracture halflength, $h$ is fracture height, $E$ is the plane-strain modulus, $R_{\mathrm{F}}$ is the fracture radius of a radial fracture. PKN model is assumed by Perkins and Kern [30] and Nordgren [31], which denotes the fracture length is larger than the fracture height while KGD is abbreviation of Khristianovich et al. [32] and Geertsma and de Klerk [33], which assumes that fracture height is more than the fracture length. Radial model occurs for fracture propagation from a point source of injection, as an intermediate condition between the two limiting cases of the PKN and KGD models.

From equation (2), we find that the fracture storage coefficient decreases with the SFL. Therefore, a slightly larger than unit slope in the fracture storage is identified, which is a new flow regime - variable fracture storage - in water injectors. In this field, the plane-strain modulus is approximately $10000 \mathrm{MPa}$, reservoir thickness is $23.9 \mathrm{~m}$.
Therefore, the fracture half-length is estimated as $49.7 \mathrm{~m}$ by PKN model.

\subsection{Case \#3: Well C}

This case examines a field case of Well $\mathrm{C}$ that seems quite common, but extremely easy to be misinterpreted if the WIF is not well realized or understood. The basic information of this well is given in Table 6 and its BHP behavior is shown in Figure 9. The pressure and its derivative curves coincide as unit slope and last about three log cycles, which signifies the severe storage effect. Due to this long storage period, the true reservoir response is masked completely. A commercial simulator (KAPPA Workstation 5.12) is used to match this pressure behavior (see Fig. 9). The interpreted reservoir permeability is $0.38 \mathrm{mD}$ and the matched storage coefficient from this long unit-slope line in the pressure and its derivative curves is considerably large as $22.7 \mathrm{~m}^{3} / \mathrm{MPa}$. Similarly, we use the method in Case \#2, the fracture half-length can also be estimated as $121.4 \mathrm{~m}$.

Different with bi-storage effect in Case \#2, the wellbore and fracture storage curve merge into single long unit slope in this case. This is because there is no extra pressure drop between wellbore and WIF, that is, the wellbore and WIF can be considered as the whole system. Since the WIF is not hold by proppant, but full of water, it would close gradually with the decreasing of BHP after shutting in the well. As a result, the water that stored in the WIF is squeezed into the formation, behaving like storage effect. If there is no pressure drop between the wellbore and WIF, it had been validated that the total storage coefficient is attributed by four parts: compressibility of water in the wellbore, change rate of wellbore volume, compressibility of water in the fracture, and change rate of fracture volume. Generally, the change rate of wellbore volume and compressibility of water in the fracture are negligible compared to another two terms [10]. Thus, the interpreted storage coefficient of $22.7 \mathrm{~m}^{3} / \mathrm{MPa}$ is actually the total storage coefficient, including wellbore and fracture. That is $[10,34]$, 
Table 6. Basic data of Well C.

(1) Well data

\begin{tabular}{lccc}
\hline Well name & $\mathrm{C}$ & Type of well & Water injector \\
\hline Water injection rate & $20 \mathrm{~m}^{3} / \mathrm{d}$ & Well bottom & $2221.63 \mathrm{~m}$ \\
Well radius & $0.12 \mathrm{~m}$ & Total compressibility & $0.00137 \mathrm{MPa}^{-1}$ \\
\hline
\end{tabular}

(2) Oil horizon and perforation data

\begin{tabular}{|c|c|c|c|c|c|}
\hline \multirow[t]{5}{*}{ Horizon } & $\begin{array}{c}\text { Reservoir interval } \\
(\mathrm{m}-\mathrm{m})\end{array}$ & Thickness (m) & Porosity (\%) & $\begin{array}{l}\text { Perforation } \\
\quad(\mathrm{m}-\mathrm{m})\end{array}$ & Thickness (m) \\
\hline & $1949.7-1954.2$ & 4.5 & \multirow{8}{*}{13.14} & & \multirow{3}{*}{3.0} \\
\hline & $1961.1-1965.0$ & 3.9 & & 1962-1965 & \\
\hline & 1965.3-1966.3 & 1.0 & & & \\
\hline & $2172.5-2175.7$ & 3.2 & & $2174-2178$ & 4.0 \\
\hline \multirow{4}{*}{$\mathrm{C} 6$} & $2176.7-2180.2$ & 3.5 & & & \\
\hline & $2180.9-2185.1$ & 4.2 & & & \\
\hline & $2185.7-2188.1$ & 2.4 & & & \\
\hline & $2189.0-2190.7$ & 1.7 & & & \\
\hline
\end{tabular}

(3) Test mode

Pressure falloff test

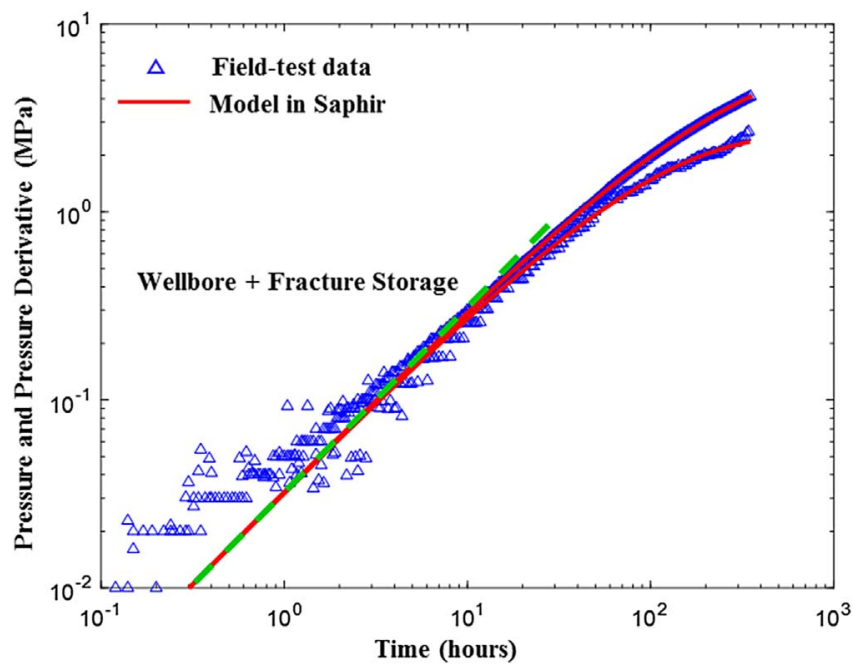

Fig. 9. History matching result of Well C by use of the Saphir.

$$
C_{\mathrm{s}}=C_{\mathrm{w}}+C_{\mathrm{f}}=c_{\text {fluid }} \cdot V_{\mathrm{w}}+C_{\mathrm{f}},
$$

where $C_{\mathrm{s}}$ is total storage coefficient, $C_{\mathrm{w}}$ is wellbore storage coefficient, $C_{\mathrm{f}}$ is fracture storage coefficient, $c_{\text {fluid }}$ is the fluid (water) compressibility, $V_{\mathrm{w}}$ is wellbore volume.

In most cases, fracture storage coefficient is several orders of magnitude larger than wellbore storage [9]. Therefore, the wellbore storage coefficient can be ignored when calculating the fracture half-length by total storage coefficient.

\subsection{Case \#4: Well D}

This case shows another "common and conventional" water injector Well D and provide us a new understanding on it.
The basic information of this well is presented in Table 7 and the BHP response is shown in Figure 10. We find that the pressure and its derivative curve coincide in the early time and then separate, followed by the upward buckling of pressure derivative curve in the late time, which is generally considered as the existence of closed boundary near the well. This closed might be caused by sedimentary facies, lithology change, the drainage areas of several other wells, and so on. Meanwhile, we found that the interpreted storage coefficient is very large, which is similar with Case \#3. One of the biggest differences of WIF and propped hydraulic fracture is that it closes gradually as the decrease of BHP during the field-testing period. As a result, the fracture conductivity is decreasing during the fracture closing process, which has a big influence on BHP response. In our previous study [10], we have validated that the DFC effect would lead to the upward buckling of pressure derivative curve in the late time. Fracture linear and bi-linear flow characteristics corresponding to 0.5 and 0.25 slopes for different conductivities may not be observed in water injectors with WIF because of the change of fracture geometry, which would not occur in producers with propped hydraulic fractures during well testing period. Using "Fracture - SFL \& DFC" model, we interpreted the Well D, shown in Figure 10. The results are given in Table 8.

The interpreted permeability is $0.37 \mathrm{mD}$, suggesting the poor flow condition around this well. The fracture-face skin is 1 . This means that there exists pressure drop in the fracture face, which may be the reason of "filter cake", caused by long time water injection. As for fracture half-length, we recommend combine two methods to decrease the uncertainty of the analysis and double check the results. One is the method presented in Case 2 by the matched considerably large storage coefficient value. The other one is conventional well testing analysis, that is, matching the typical 
Table 7. Basic data of Well D.

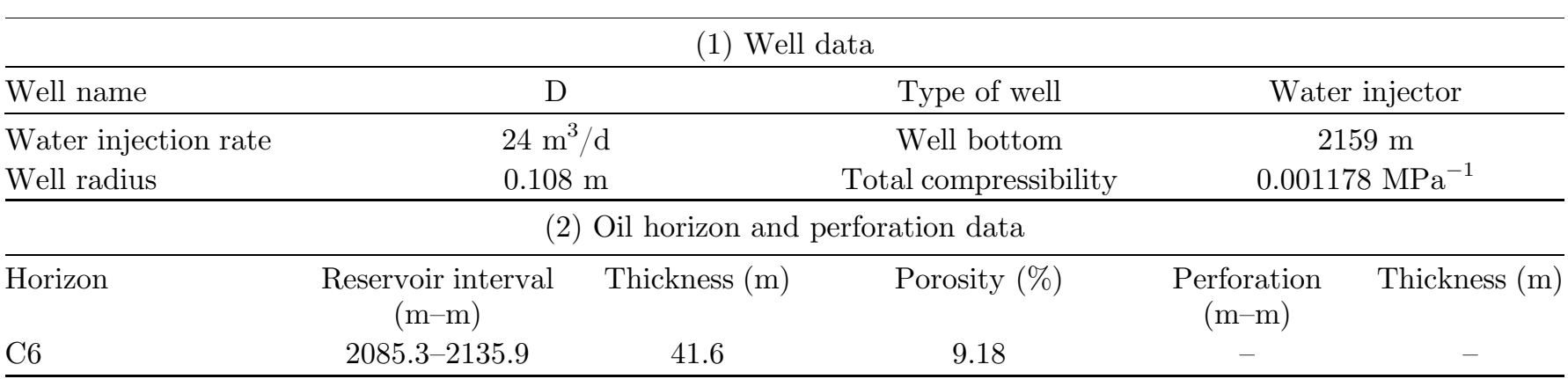

(3) Test mode

Pressure falloff test

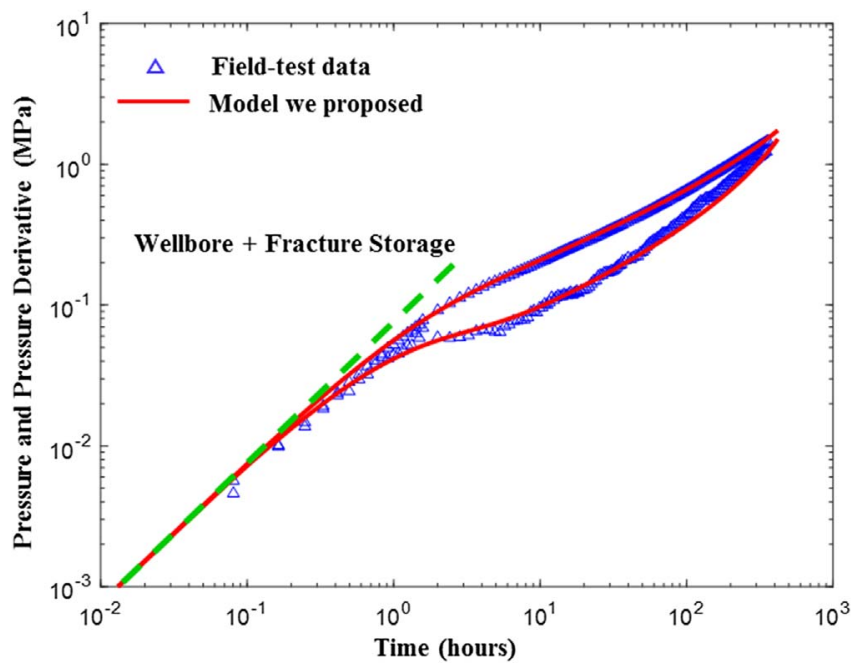

Fig. 10. History matching result of Well D by use of the model we proposed.

curve with measured pressure data. In theory, the fracture half-length values estimated by these two methods should be very close to each. However, due to the uncertainty of formation parameters and the non-uniqueness results of pressure-transient analysis, neither of these methods are that reliable for the field cases. For Well D, the matched storage coefficient is $43.3 \mathrm{~m}^{3} / \mathrm{MPa}$, which should not be wellbore storage coefficient only that presented in Case \#3. Anand and Subrahmanyam [9] demonstrated that the fracture storage coefficient $\gg$ wellbore storage coefficient. Therefore, $C_{\mathrm{f}} \approx 43.3 \mathrm{~m}^{3} / \mathrm{MPa}$ in this case, which is used to calculate fracture half-length as $73.5 \mathrm{~m}$ via equation (2). This is consistent with the fracture half-length (90 m) matched by "Fracture - SFL \& DFC" model.

The meaning of this example is that it reminds us the upward buckling of pressure derivative of water injector in the late time may not necessarily related to closed boundary, but the decreasing of fracture conductivity caused by fracture closing process.
Table 8. Well testing interpretation results for Well D.

\begin{tabular}{lcccc}
\hline Well & $\begin{array}{c}\text { Storage } \\
\text { coefficient } \\
\left(\mathrm{m}^{3} / \mathrm{MPa}\right)\end{array}$ & $\begin{array}{r}\text { Permeability Fracture- Fracture } \\
(\mathrm{mD})\end{array}$ & $\begin{array}{c}\text { face } \\
\text { skin }\end{array}$ & $\begin{array}{c}\text { half- } \\
\text { length } \\
(\mathrm{m})\end{array}$ \\
\hline $\begin{array}{l}\text { Fracture - } \\
\text { SFL \& DFC }\end{array}$ & 43.3 & 0.37 & 1 & 90 \\
\hline
\end{tabular}

\subsection{Case \#5: Well E}

Some evidences show that waterflooding may also induce multiple fractures during long time water injection [35]. Compared with single fracture closure, the characterization of the closure of multiple fractures is much more complicated. According to equation (1), we conclude that the fracture open/closure pressure varies in different directions, which increases with the increase of $\theta$. Specially, fracture closure pressure is equal to $\sigma_{\min }$ and $\sigma_{\max }$ in maximum and minimum principal stress directions, respectively. Because the different stress condition perpendicular to the fracture walls, the WIFs would not close simultaneously, but successively. Assuming the same pressure system in the fractures, Liu and Economides [36, 37] proposed a mathematical model to describe the multiple closures in Mini-Frac analysis based on the classical Carter's model, which indicates that the rate of fluid loss decreases with time at any point along the fracture. Leak-off coefficient is used to characterize the fluid loss ability from fracture into matrix and the rate of fluid flow behavior can be represented as $q_{L}=\frac{2 C_{\mathrm{L}} A}{\sqrt{t-\tau}}$, among which $C_{\mathrm{L}}$ is leak-off coefficient, $q_{\mathrm{L}}$ is fluid-loss rate, $A$ is the element of the fracture area, $t$ is the time measured from the start of pumping, $\tau$ is the time when fracture is created or opened. He assumed that each fracture (main and secondary fractures) has own leak-off coefficient and area, which makes his model very limited due to too many unknown parameters need to be solved. Applying Liu's research in Mini-Frac analysis to waterflooding field, we propose a new "Multiple Fracture 
Table 9. Basic data of Well E.

(1) Well data

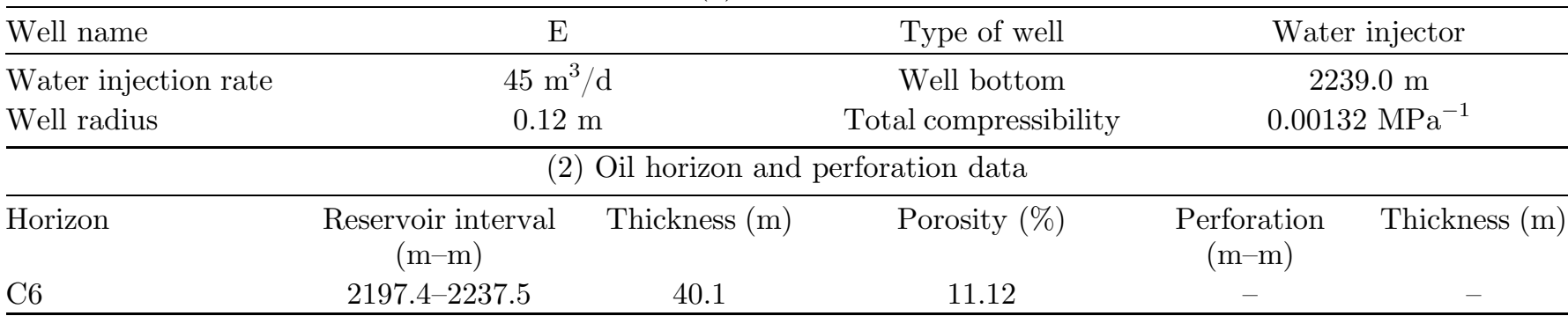

(3) Test mode

Pressure falloff test

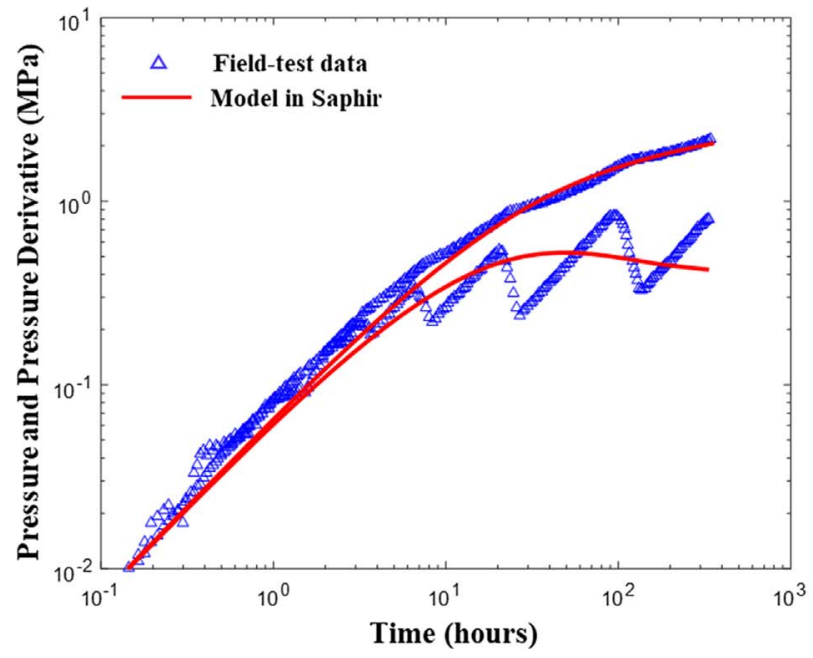

(a)

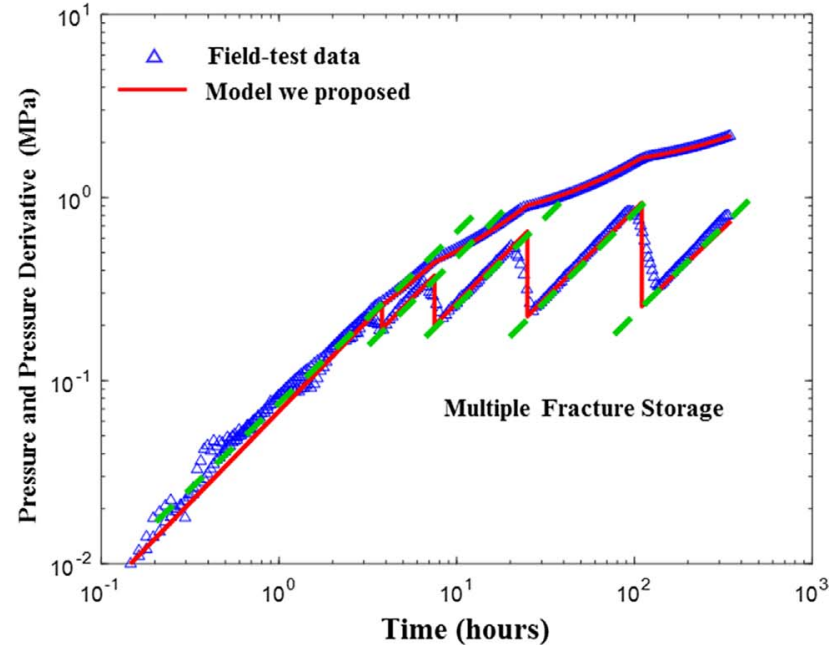

(b)

Fig. 11. Comparison of the matching results of Well E between (a) Saphir and (b) Model we proposed.

Closures" model, in which the closure of WIFs are equivalent to the decrease of leak-off rate (the rate at which a fracturing fluid flows from the fracture into the surrounding formation) in the main fracture (Appendix B) [11]. We find that $3 / 2$ slope recognized by Mohamed et al. [38] in Mini-Frac analysis would not appear in waterflooding, but unit slope instead, which can be interpreted as fracture storage effect.

The basic information and the BHP responses of Well E are shown in Table 9 and Figure 11, respectively. Several characteristics are identified.

- The pressure drop slows down repeatedly and the pressure derivative shows multiple fluctuations.

- Several unit slopes in the pressure derivative are identified.

- Storage coefficient interpreted by the commercial simulator is considerably large as $7.93 \mathrm{~m}^{3} / \mathrm{MPa}$, and the interpreted permeability is $3.14 \mathrm{mD}$.
Firstly, a commercial simulator (KAPPA Workstation 5.12) is used to interpret this pressure behavior and the matching result is shown in Figure 11a. We find that the fluctuations of pressure derivative curve cannot match by current models. In our previous paper [11], we have comprehensively discussed that such pressure characteristics shown above may be cause by multiple fracture closures during the shutting in period. In this case, five fractures are assumed since there are five unit slopes in the pressure derivative curve. Interpreted by our "Multiple Fracture Closures" model, we match the pressure behavior, which is shown in Figure 11b. The interpretation results of leak-off coefficient for each fracture are $C_{\mathrm{Lm} 1}=0.4 \mathrm{~m} / \mathrm{h}^{0.5}, C_{\mathrm{Lm} 2}=$ $0.3 \mathrm{~m} / \mathrm{h}^{0.5}, C_{\mathrm{Lm} 3}=0.16 \mathrm{~m} / \mathrm{h}^{0.5}, C_{\mathrm{Lm} 4}=0.055 \mathrm{~m} / \mathrm{h}^{0.5}$, $C_{\mathrm{Lm} 5}=0.015 \mathrm{~m} / \mathrm{h}^{0.5}$. By the equation $C_{\mathrm{L}}=$ $0.563 \Delta p \sqrt{\frac{k \phi C_{\mathrm{t}}}{\mu}}[34]$, we can obtain the reservoir permeability as $0.16 \mathrm{mD}$, which is consistent with the formation permeability in this field. 


\section{Conclusion}

This work intends to show a comprehensive analysis of pressure responses in water injection wells considering the influence of WIF(s). After interpreting several hundreds of water injection wells in Changqing Oilfield, China, we find that the BHP performances of water injectors with WIF(s) are much more complicated compared with fractured producers due to the variation of fracture properties. Aiming at five representative types of BHP responses, we innovatively analyze them by combining a commercial simulator (KAPPA Workstation 5.12) and our new models to get a new understanding of water injector behaviors. Results show that the closing of WIF(s) during the field testing period should be paid particular attentions when interpreting the BHP behaviors. If they are not well realized or characterized, misleading interpretation results may be obtained.

Acknowledgments. The authors thank the financial supports from National Natural Science Foundation of China (No. 11872073) and National Science and Technology Major Projects (No. 2017ZX05013002). We also would like to thank the PetroChina Ltd. in Changqing Oilfield for providing data for our studies. An earlier version of this work was presented as a conference paper at the SPE Improved Oil Recovery Conference held in Tulsa, Oklahoma, USA as SPE 190264 and the feedback obtained from colleagues in this forum is greatly appreciated.

\section{References}

1 Koning E.J.L. (1988) Waterflooding under fracturing conditions, PhD Thesis, Technical Univerisity of Delft, The Netherlands.

2 Ovens J.E.V., Larsen F.P., Cowie D.R. (1997) Making sense of water injection fractures in the Dan field, in: Paper Presented at SPE Annual Technical Conference and Exhibition, 5-8 October, San Antonio, Texas. SPE-38928-MS.

3 Izgec B., Kabir C.S. (2009) Real-time performance analysis of water-injection wells, SPE Res. Evalu. Eng. 12, 1, 116123. SPE-109876-PA.

4 Wang Y., Cheng S., Feng N., He Y., Yu H. (2017) The physical process and pressure-transient analysis considering fractures excessive extension in water injection wells, J. Pet. Sci. Eng. 151, 2017, 439-454.

5 He Y., Cheng S., Li S., Huang Y., Qin J., Hu L., Yu H. (2017) A semianalytical methodology to diagnose the locations of underperforming hydraulic fractures through pressure-transient analysis in tight gas reservoir, SPE J. 22, 3, 924-939. SPE-185166-PA.

6 Gadde P.B., Sharma M.M. (2001) Growing injection well fractures and their impact on waterflood performance, in: Paper Presented at SPE Annual Technical Conference and Exhibition, 30 September-3 October, New Orleans, Louisiana. SPE-71614-MS.

7 Hustedt B., Zwarts D., Bjoerndal H.P. (2006) Induced fracturing in reservoir simulations: Application of a new coupled simulator to waterflooding field examples, in: Paper Presented at SPE Annual Technical Conference and Exhibition, 24-27 September, San Antonio, Texas. SPE-102467-MS.
8 Wright C.A., Weijers L., Davis E.J., Mayerhofer M. (1999) Understanding hydraulic fracture growth: Tricky but not hopeless, in: Paper Presented at SPE Annual Technical Conference and Exhibition, 3-6 October, Houston, Texas. SPE-56724-MS.

9 Anand A., Subrahmanyam S.G.V. (2014) Induced fracture modelling and its integration with pressure transient analysis: Study for Shallow-water Offshore Field, South-East Asia - Part 1, in: Paper Presented at Abu Dhabi International Petroleum Exhibition and Conference, 10-13 November, Abu Dhabi, UAE. SPE-171882-MS.

10 Wang Y., Cheng S., Zhang K., Ayala L.F. (2019) Investigation on the transient pressure response of water injector coupling the dynamic flow behaviors in the wellbore, waterflood-induced fracture and reservoir: Semi-analytical modeling and a field case, Int. J. Heat Mass Trans. 130, 2019, 668-679.

11 Wang Y., Cheng S., Zhang K., He Y., Yu H. (2019) Pressuretransient analysis of water injectors considering the multiple closures of waterflood-induced fractures in tight reservoir: Case studies in Changqing Oilfield, China, J. Pet. Sci. Eng. 172, 2019, 643-653.

12 Baker R., Dieva R., Jobling R., Lok C. (2016) The myths of waterfloods, EOR floods and how to optimize real injection schemes, in: Paper Presented at SPE Improved Oil Recovery Conference, 11-13 April, Tulsa, Oklahoma. SPE-179536-MS.

13 Morales R.H., Abou-Sayer A.S., Jones A.H., Al-Saffar A. (1986) Detection of a formation fracture in a waterflooding experiment, J. Pet. Technol. 38, 10, 1113-1121.

14 Heffer K.J., Fox R.J., McGill C.A., Koutsabeloulis N.C. (1997) Novel techniques show links between reservoir flow directionality, earth stress, fault structure and geomechanical changes in mature waterfloods, SPE J. 2, 2, 91-98. SPE30711-PA.

15 van Dam D.B., Pater C.J., Romijn R. (1998) Analysis of hydraulic fracture closure in laboratory experiments, in: Paper Presented at SPE/ISRM Rock Mechanics in Petroleum Engineering, 8-10 July, Trondheim, Norway. SPE-47380-MS.

16 Su H., Lei Z., Zhang D., Li J., Zhang Z., Ju B., Li Z. (2017) Dynamic and static comprehensive prediction method of natural fractures in fractured oil reservoirs: A case study of Triassic Chang 63 reservoirs in Huaqing Oilfield, Ordos Basin, NW China, Petrol. Explor. Dev. 44, 6, 972-982.

17 Morse J.V., Ott III F. (1967) Field Application of unsteadystate pressure analyses in reservoir diagnosis, J. Pet. Technol. 19, 7, 869-876. SPE-1514-PA.

18 Kazemi H., Merrill L.S., Jargon J.R. (1972) Problems in interpretation of pressure fall-off tests in reservoirs with and without fluid banks, J. Pet. Technol. 24, 9, 1147-1156. SPE3696-PA.

19 Abbaszadeh M., Kamal M. (1989) Pressure-transient testing of water-injection wells, SPE Res. Eng. 4, 1, 115-124. SPE16744-PA.

20 Kong X., Lu D. (1991) Pressure falloff analysis of water injection well, Society of Petroleum Engineers. SPE-23419MS.

21 Wang Y., Cheng S., Zhang K., He Y., Feng N., Qin J., Luo L., Yu H. (2019) A comprehensive work flow to characterize waterflood-induced fracture by integrating real-time monitoring, formation test, and dynamic production analysis applied to Changqing Oilfield, China, SPE Res. Evalu. Eng. 22, 692-708. Preprint. SPE-191370-PA. 
22 Larsen L., Bratvold R.B. (1994) Effects of propagating fractures on pressure-transient injection and falloff data, SPE Form. Evalu. 9, 2, 105-114.

23 Spivey J.P., Lee W.J. (1999) Variable wellbore storage models for a dual-volume wellbore, in: Paper Presented at SPE Annual Technical Conference and Exhibition, 3-6 October, Houston, Texas. SPE-56615-MS.

24 van den Hoek P.J. (2002) Pressure transient analysis in fractured produced water injection wells, in: Paper Presented at SPE Asia Pacific Oil and Gas Conference and Exhibition, 8-10 October, Melbourne, Australia. SPE-77946-MS.

25 van den Hoek P.J. (2005) A novel methodology to derive the dimensions and degree of containment of waterflood-induced fractures from pressure transient analysis, in: Paper Presented at SPE Annual Technical Conference and Exhibition, 5-8 October, Denver, Colorado. SPE-84289-MS.

26 Craig D.P., Blasingame T.A. (2005) A new refracturecandidate diagnostic test determines reservoir properties and identifies existing conductive or damaged fractures, in: Paper Presented at SPE Annual Technical Conference and Exhibition, 9-12 October, Dallas, Texas. SPE-96785-MS.

27 Craig D.P., Blasingame T.A. (2006) Application of a new fracture-injection/falloff model accounting for propagating, dilated, and closing hydraulic fractures, in: Paper Presented at SPE Gas Technology Symposium, 15-17 May, Calgary, Alberta, Canada. SPE-100578-MS.

28 Rizwan Y. (2017) Pressure transient analysis for Minifracs/ DFIT and waterflood induced fractures, Master Thesis, Technical Univerisity of Delft, The Netherlands.

29 BinAkresh S.A., Rahman N.M.A. (2015) Modeling pressuretransient data for characterizing the formation damage in water injection wells operating above the fracturing pressure, in: Paper Presented at SPE European Formation Damage Conference and Exhibition, 3-5 June, Budapest, Hungary. SPE-174278-MS.

30 Perkins T.K., Kern L.R. (1961) Widths of hydraulic fractures, J. Pet. Technol. 13, 9, 937-949. SPE-89-PA.

31 Nordgren R.P. (1972) Propagation of a vertical hydraulic fracture, SPE J. 12, 4, 306-314. SPE-3009-PA.

32 Khristianovich S.A., Zheltov Y.P., Barenblatt G.I., Maximovich G.K. (1959) Theoretical principles of hydraulic fracturing of oil strata, in: Paper Presented at 5th World Petroleum Congress, New York.
33 Geertsma J., de Klerk F. (1969) A rapid method of predicting width and extent of hydraulic induced fractures, J. Pet. Technol. 21, 12, 1571-1581. SPE-2458-PA.

34 McClure M.W., Jung Hojung, Cramer D.D., Sharma M.M. (2016) The fracture-compliance method for picking closure pressure from diagnostic fracture-injection tests, SPE J. 21, 4, 1321-1339. SPE-179725-PA.

35 He Y., Cheng S., Li L., Mu G., Zhang T., Xu H., Qin J., Yu H. (2017) Waterflood direction and front characterization with four-step work flow: A case study in Changqing Oil field, China, SPE Res Evalu. Eng. 20, 3, 708-725. SPE178053-PA.

36 Liu G., Economides C.E. (2015) Comprehensive global model for before-closure analysis of an injection falloff fracture calibration test, in:Paper Presented at SPE Annual Technical Conference and Exhibition, 28-30 September, Houston, Texas. SPE-174906-MS.

37 Liu G., Economides C.E. (2016) Interpretation methodology for fracture calibration test before-closure analysis of normal and abnormal leakoff mechanisms, in: Paper Presented at SPE Hydraulic Fracturing Technology Conference, 9-11 February, The Woodlands, Texas. SPE-179176-MS.

38 Mohamed I.M., Azmy R.M., Sayed M.A., Marongiu-Porcu M., Economides C. (2011) Evaluation of after-closure analysis techniques for tight and shale gas formations, in: Paper Presented at SPE Hydraulic Fracturing Technology Conference, 24-26 January, The Woodlands, Texas. SPE-140136-MS.

39 Pedrosa O.A. Jr. (1986) Pressure transient response in stress-sensitive formations, in: Paper Presented at SPE California Regional Meeting, 2-4 April, Oakland, California. SPE-15115-MS.

40 Stehfest H. (1970) Algorithm 368: Numerical inversion of Laplace transforms [D5], Commun. ACM 13, 1, 47-49.

41 Nolte K. (1979) Determination of fracture parameters from fracturing pressure decline, in: Paper Presented at the SPE Annual Technical Conference and Exhibition, 23-26 September, Las Vegas, Nevada. SPE-8341-MS.

42 Nolte K.G. (1986) A general analysis of fracturing pressure decline with application to three models, SPE Form. Evalu. 6, 1, 571-583. SPE-12941-PA.

43 Valko P.P., Economides M.J. (1999) Fluid-leakoff delineation in high-permeability fracturing, SPE Prod. Facil. 14, 02, 110-116. SPE-56135-PA. 


\section{Appendix A}

\section{Derivation of the closure of single WIF considering properties variations}

We assume that the reservoir is isothermal, homogenous, isotropic and of uniform thickness and porosity. Sing water phase flow in the WIF and reservoir. The dimensionless parameters are defined.

Dimensionless pressure,

$$
\begin{gathered}
\xi_{\mathrm{wD} j}=\frac{2 \pi k_{\mathrm{m}} h\left(\xi_{\mathrm{shut}-\mathrm{in}}-\xi_{\mathrm{w} j}\right)}{q \mu B} \quad j=1,2,3,4, \\
p_{\mathrm{wD}}=\frac{2 \pi k_{\mathrm{m}} h\left(p_{\text {shut }-i n}-p_{\mathrm{w}}\right)}{q \mu B} .
\end{gathered}
$$

Dimensionless pressure,

$$
t_{\mathrm{D}}=\frac{k_{\mathrm{m}} t}{\phi \mu c_{\mathrm{t}} x_{\mathrm{F} 0}^{2}} .
$$

Dimensionless wellbore storage coefficient and fracture storage coefficient,

$$
\begin{gathered}
C_{\mathrm{wD}}=\frac{C_{\mathrm{w}}}{2 \pi \phi c_{\mathrm{t}} h x_{\mathrm{F} 0}^{2}}, \\
C_{\mathrm{fD}}=\frac{C_{\mathrm{f}}}{2 \pi \phi c_{\mathrm{t}} h x_{\mathrm{F} 0}^{2}} .
\end{gathered}
$$

Dimensionless fracture conductivity in the shut-in moment,

$$
C_{\mathrm{FD} 0}=\frac{\left(k_{\mathrm{F}} w\right)_{0}}{k_{\mathrm{m}} x_{\mathrm{F} 0}}
$$

Diffusivity ratio,

$$
\eta_{\mathrm{FD}}=\frac{\left(\phi \mu c_{\mathrm{t}} / k\right)_{\mathrm{m}}}{\left(\phi \mu c_{\mathrm{t}} / k\right)_{\mathrm{F}}}
$$

Dimensionless stress-sensitivity coefficient,

$$
\gamma_{\mathrm{D}}=\frac{q \mu B}{2 \pi k_{\mathrm{m}} h} \cdot \gamma \text {. }
$$

Compared with current methods, the key and novelty of our model is that SFL and DFC effects are considered. We divide the whole system into three sections: wellbore, WIF and reservoir. The relationship between wellbore, WIF and reservoir is shown in Figure A1. The wellbore and WIF are linked by choked-fracture skin $\left(S_{\text {choke }}\right)$ while the WIF and reservoir are connected by fracture face skin $\left(S_{\mathrm{fs}}\right)$. The brief derivation of our model is presented below.

The decreasing of fracture conductivity/permeability is assumed as,

$$
\gamma=\frac{1}{k_{\mathrm{F}}} \frac{\mathrm{d} k_{\mathrm{F}}}{\mathrm{d} p_{\mathrm{F}}} .
$$

Considering the stress sensitivity in the WIF and the constant pressure out boundary condition, the BHP solution of bi-linear flow can be written as [10],

$$
\bar{\xi}_{\mathrm{wD} 1}=\frac{\pi}{s C_{\mathrm{FD} 0} \sqrt{\beta} \tan h(\sqrt{\beta})},
$$

where,

$$
\begin{gathered}
p_{\mathrm{wD}}=-\frac{1}{\gamma_{\mathrm{D}}} \ln \left(1-\gamma_{\mathrm{D}} \xi_{\mathrm{wD}}\right), \\
\beta=\frac{s}{\eta_{\mathrm{FD}}}+\frac{2 \sqrt{s}}{C_{\mathrm{FD} 0}} .
\end{gathered}
$$

The reason we use $\xi_{\mathrm{wD}}$ is that the differential equation in the fracture region is strong-nonlinear when DFC effect is considered. On the other hand, since the differential equation is nonlinear, the superposition principle is not applicable. Therefore, the Pedrosa substitution [39] is applied to eliminate this nonlinearity, which is given in equation (A-11). Experiments show that the fracture shrinks from the tip first, then subsequently towards the wellbore [15], which can be expressed as [25],

$$
x_{\mathrm{F}}\left(p_{\mathrm{wD}}\right)=x_{\mathrm{F} 0} \cdot\left(1-\frac{p_{\mathrm{wD}}^{0}-p_{\mathrm{wD}}}{\text { delpat }}\right),
$$

where $p_{\mathrm{wD}}^{0}$ is the dimensionless pressure where lengthwise shrinkage starts, and the parameter "delpat" is fracture length shrinkage coefficient, which is used to measure how fast the WIF closes.

The dimensionless pressure solution outside of wellbore in the fracture is obtained based on Duhamel's principle,

$$
\begin{aligned}
\xi_{\mathrm{wD} 3}\left(t_{\mathrm{D}}\right)= & \int_{0}^{t_{\mathrm{D}}}\left[1-C_{\mathrm{fD}}\left[\xi_{\mathrm{wD} 3}\left(\tau_{\mathrm{D}}\right)\right] \frac{\partial \xi_{\mathrm{wD} 3}\left(\tau_{\mathrm{D}}\right)}{\partial \tau_{\mathrm{D}}}\right] \\
& \cdot \frac{\partial \xi_{\mathrm{wD} 2}\left(t_{\mathrm{D}}-\tau_{\mathrm{D}}\right)}{t_{\mathrm{D}}} \partial \tau_{\mathrm{D}},
\end{aligned}
$$

where,

$$
\xi_{\mathrm{wD} 2}\left(t_{\mathrm{D}}\right)=\xi_{\mathrm{wD} 1}\left(t_{\mathrm{D}}\right)+S_{\mathrm{fs}},
$$

and $S_{\mathrm{fs}}$ is fracture-face skin.

Finally, we can obtain the BHP by taking choked-fracture skin and wellbore storage into account,

$$
\bar{\xi}_{\mathrm{wD}}\left(t_{\mathrm{D}}\right)=\frac{s \bar{\xi}_{\mathrm{wD} 3}+S_{\text {choke }}}{s\left[1+s C_{\mathrm{wD}}\left(s \bar{\xi}_{\mathrm{wD} 3}+S_{\text {choke }}\right)\right]},
$$

where $S_{\text {choke }}$ is the choked-fracture skin.

Applying Stehfest inversion [40], the $\bar{\xi}_{\mathrm{wD}}$ can be translated into $\xi_{\mathrm{wD}}$ in time domain. Then, the inversion of Pedrosa substitution [39] is applied, the BHP response in water injection well with WIF can be achieved. 
Reservoir

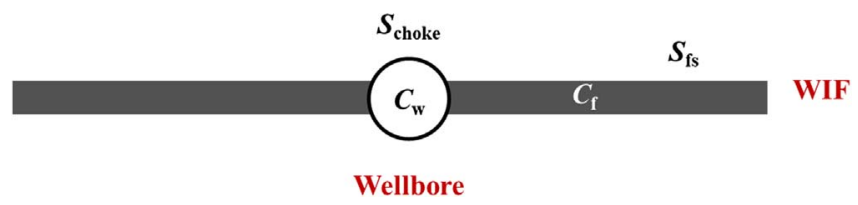

Fig. A1. Schematic of relationship between wellbore, WIF and reservoir.

\section{Appendix B}

\section{Derivation of multiple closures of WIFs modelling}

We use the models presented by [41, 42], Liu and Economides $[36,37]$ as a starting point. Mini-Frac analysis and material balance function are combined to derive the BHP response of water injector with multiple WIFs. We assume the main and secondary fractures share the same pressure system. The abbreviated derivation of the model is developed below.

The relationship between fracture width and net pressure is defined as,

$$
c_{\mathrm{f}}=\frac{\bar{w}}{p_{\text {net }}},
$$

where $c_{\mathrm{f}}$ is fracture compliance, $\mathrm{m} / \mathrm{MPa} ; \bar{w}$ is average fracture width, $\mathrm{m} ; p_{\text {net }}$ is the net pressure on fracture surface, which can be calculated as,

$$
p_{\text {net }}=p_{\text {frac }}(t)-\sigma_{\text {resistant }}=p_{\mathrm{w}}(t)-\sigma_{\text {resistant }},
$$

and $\sigma_{\text {resistant }}$ is the confining stress on the fracture face, $\mathrm{MPa}$.

Average fracture width is,

$$
\bar{w}=\frac{V_{\text {frac }}}{A} .
$$

For the falloff analysis, we define $\Delta p_{\mathrm{w}}(t)$ as,

$$
\Delta p_{\mathrm{w}}(t)=p_{\mathrm{ws}}-p_{\mathrm{w}}(t),
$$

where $p_{\mathrm{ws}}$ is the BHP in the shut-in moment, MPa; $p_{\mathrm{w}}$ is BHP, MPa.

Combining equations (B-1)-(B-4) yields,

$$
\frac{\mathrm{d} \Delta p_{\mathrm{w}}}{\mathrm{d} t}=-\frac{\mathrm{d} p_{\text {net }}(t)}{\mathrm{d} t}=-\frac{\mathrm{d}}{\mathrm{d} t}\left(\frac{\bar{w}}{c_{\mathrm{f}}}\right)=-\frac{\mathrm{d}}{\mathrm{d} t}\left(\frac{V_{\text {frac }}}{c_{\mathrm{f}} A}\right) .
$$

If a main fracture and three secondary fractures are assumed and each fracture has its flow coefficient and fracture area. The pressure drop in these fractures is ignored. According to material balance function, we have,

$$
\begin{gathered}
V_{\mathrm{l}, \mathrm{mf}}+V_{\text {frac,mf }}+V_{\mathrm{l}, \mathrm{bf} 1}+V_{\text {frac,bf } 1}+V_{\mathrm{l}, \mathrm{bf} 2}+V_{\text {frac,bf2 }} \\
+V_{\mathrm{l}, \mathrm{bf} 3}+V_{\text {frac,bf3 }}=V_{\mathrm{p}} .
\end{gathered}
$$

The flow volume from main fracture and secondary fractures to matrix is [36],

$$
\begin{aligned}
& V_{\mathrm{l}, \mathrm{mf}}=4 r_{\mathrm{p}} C_{\mathrm{Lm}} \sqrt{t_{\mathrm{p}}} A_{\mathrm{fm}} g\left(\Delta t_{\mathrm{D}}, \alpha\right) \\
& V_{\mathrm{l}, \mathrm{bf} 1}=4 r_{\mathrm{p}} C_{\mathrm{Lb} 1} \sqrt{t_{\mathrm{p}}} A_{\mathrm{fb} 1} g\left(\Delta t_{\mathrm{D}}, \alpha\right) \\
& V_{\mathrm{l}, \mathrm{bf} 2}=4 r_{\mathrm{p}} C_{\mathrm{Lb} 2} \sqrt{t_{\mathrm{p}}} A_{\mathrm{fb} 2} g\left(\Delta t_{\mathrm{D}}, \alpha\right) \\
& V_{\mathrm{l}, \mathrm{bf} 3}=4 r_{\mathrm{p}} C_{\mathrm{Lb} 3} \sqrt{t_{\mathrm{p}}} A_{\mathrm{fb} 3} g\left(\Delta t_{\mathrm{D}}, \alpha\right)
\end{aligned} .
$$

This $g$ function is defined by [41] and later reformulated by [43]. It gives the ratio of the flow rate from fracture into the matrix to the quantity $4 C_{\mathrm{L}} A_{\mathrm{f}} \mathrm{t}_{\mathrm{p}}{ }^{0.5}$, but now is valid for all times greater than the end of pumping while $g_{0}$ gave the ratio only at one time point, namely exactly at the end of pumping (Valko and Economides, 1999),

$$
g\left(\Delta t_{\mathrm{D}}, \alpha\right)=2 \int_{0}^{1} \sqrt{1+\Delta t_{\mathrm{D}}-\xi^{1 / \alpha}} \mathrm{d} \xi,
$$

where $\alpha$ is area exponent, which ranges from $1 / 2$ to 1 .

Combining equations (B-1) through (B-5) and integrating, yields,

\section{See equation (9) below}

where,

$$
\Delta t_{\mathrm{D}}=\frac{\Delta t}{t_{\mathrm{p}}}
$$

$$
A_{\mathrm{frbi}}=\frac{A_{\mathrm{fbi}}}{A_{\mathrm{fm}}} \quad i=1,2,3,
$$

$$
G\left(\Delta t_{\mathrm{D}}\right)=\frac{4}{\pi}\left[g\left(\Delta t_{\mathrm{D}}\right)-g_{0}\right],
$$

$$
p_{\mathrm{w}}(\Delta t)=\left\{\begin{array}{l}
p_{\mathrm{shut}-\mathrm{in}}-\frac{\pi r_{\mathrm{p}} \sqrt{t_{\mathrm{p}}}}{c_{\mathrm{fm}}}\left(C_{\mathrm{Lm}}+C_{\mathrm{Lb} 1} A_{\mathrm{frb} 1}+C_{\mathrm{Lb} 2} A_{\mathrm{frb} 2}+C_{\mathrm{Lb} 3} A_{\mathrm{frb} 3}\right) G\left(\Delta t_{\mathrm{D}}, \alpha\right) \quad 0 \leq \Delta t \leq \Delta t_{\mathrm{fc} 1} \\
p_{\mathrm{f} 1}-\frac{\pi r_{\mathrm{p}} \sqrt{t_{\mathrm{p}}}}{c_{\mathrm{fm}}}\left(C_{\mathrm{Lm}}+C_{\mathrm{Lb} 1} A_{\mathrm{frb} 1}+C_{\mathrm{Lb} 2} A_{\mathrm{frb} 2}\right)\left[G\left(\Delta t_{\mathrm{D}}, \alpha\right)-G\left(\Delta t_{\mathrm{fcD} 1}, \alpha\right)\right] \quad \Delta t_{\mathrm{fc} 1} \leq \Delta t \leq \Delta t_{\mathrm{fc} 2} \\
p_{\mathrm{f} 2}-\frac{\pi r_{\mathrm{p}} \sqrt{t_{\mathrm{p}}}}{c_{\mathrm{fm}}}\left(C_{\mathrm{Lm}}+C_{\mathrm{Lb} 1} A_{\mathrm{frb} 1}\right)\left[G\left(\Delta t_{\mathrm{D}}, \alpha\right)-G\left(\Delta t_{\mathrm{fcD} 2}, \alpha\right)\right] \quad \Delta t_{\mathrm{fc} 2} \leq \Delta t \leq \Delta t_{\mathrm{fc} 3} \\
p_{\mathrm{f} 3}-\frac{\pi r_{\mathrm{p}} \sqrt{t_{\mathrm{p}}} C_{\mathrm{Lm}}}{c_{\mathrm{fm}}}\left[G\left(\Delta t_{\mathrm{D}}, \alpha\right)-G\left(\Delta t_{\mathrm{fcD} 3}, \alpha\right) G\left(\Delta t_{\mathrm{D}}, \alpha\right)-G\left(\Delta t_{\mathrm{fcD} 3}, \alpha\right)\right] \quad \Delta t \geq \Delta t_{\mathrm{fc} 3}
\end{array}\right.
$$




$$
g_{0}=g\left(\Delta t_{\mathrm{D}}=0\right)
$$

Then, we can get

Even though above model is more accurate, which investigates the properties of main fracture and secondary fracture separately. It is very limited because there are too many unknown parameters need to be determined. Thus, a simplified model is proposed based on Liu and Economides [36]. The closure of fractures is considered as the decreasing of leak-off coefficient in the main fracture.

\section{See equation (14) below}

where $C_{\mathrm{Lm} 1}, C_{\mathrm{Lm} 2}, C_{\mathrm{Lm} 3}$, and $C_{\mathrm{Lm} 4}$ are the equivalent leakoff coefficient in the fractured falloff period, $\mathrm{m} / \mathrm{h}^{0.5}$.

$$
p_{\mathrm{w}}(\Delta t)=\left\{\begin{array}{l}
p_{\text {shut }-\mathrm{in}}-\frac{\pi r_{\mathrm{p}} \sqrt{t_{\mathrm{p}}} C_{\mathrm{Lm} 1}}{c_{\mathrm{fm}}} G\left(\Delta t_{\mathrm{D}}, \alpha\right) \quad 0 \leq \Delta t \leq \Delta t_{\mathrm{fc} 1} \\
p_{\mathrm{f} 1}-\frac{\pi r_{\mathrm{p}} \sqrt{t_{\mathrm{p}}} C_{\mathrm{Lm} 2}}{c_{\mathrm{fm}}}\left[G\left(\Delta t_{\mathrm{D}}, \alpha\right)-G\left(\Delta t_{\mathrm{fcD} 1}, \alpha\right)\right] \quad \Delta t_{\mathrm{fc} 1} \leq \Delta t \leq \Delta t_{\mathrm{fc} 2} \\
p_{\mathrm{f} 2}-\frac{\pi r_{\mathrm{p}} \sqrt{t_{\mathrm{p}}} C_{\mathrm{Lm} 3}}{c_{\mathrm{fm}}}\left[G\left(\Delta t_{\mathrm{D}}, \alpha\right)-G\left(\Delta t_{\mathrm{fcD} 2}, \alpha\right)\right] \quad \Delta t_{\mathrm{fc} 2} \leq \Delta t \leq \Delta t_{\mathrm{fc} 3} \\
p_{\mathrm{f} 3}-\frac{\pi r_{\mathrm{p}} \sqrt{t_{\mathrm{p}}} C_{\mathrm{Lm} 4}}{c_{\mathrm{fm}}}\left[G\left(\Delta t_{\mathrm{D}}, \alpha\right)-G\left(\Delta t_{\mathrm{fcD} 3}, \alpha\right)\right] \quad \Delta t \geq \Delta t_{\mathrm{fc} 3},
\end{array}\right.
$$

